Munich) described the Munich/Frascati data since August 1973, claiming a substantial improvement on sensitivity over Weber, but with no significant events detected. R. Drever described data from his wide bandwidth detector in Glasgow during the period September 1972-April 1973 with the same result-no effect. $\mathrm{He}$ described the situation as "saddening" and went as far as to express the opinion that Weber was probably mistaken. Finally, J. Tyson (Bell Telephone), claiming a sensitivity for the Bell Laboratories / Rochester experiment very much greater than other experiments, also reported no events.

In view of the importance of the issue at stake, the atmosphere remained remarkably restrained. Weber countered the negative results of his colleagues by rejecting their claims of higher sensitivity. When challenged on the allimportant issues of the sidereal anisotropy (which seems to indicate a correlation of his events with the centre of the galaxy), Weber seemed to be saying that he had not yet checked recent data for this effect because of other pressures. The overall impression was that the issues involved hinge on complicated technioal details, but that Weber's position among the experimentalists is now growing increasingly isolated as more and more experiments fail to confirm his data.

\section{Stranded whales in Britain}

\section{from our \\ Marine Vertebrate Correspondent}

THE gathering of data on stranded cetaceans on the coast of the British Isles has now been in progress for well over half a century. Because of the special historical claim that the Crown had over 'royal fishes' on much of the English, Welsh and Scottish coasts, the collection of reports of strandings was already in progress and their publication on a regular basis was a logical step which was initiated by the late Sir Sidney Harmer in 1913.

The latest Report on Cetacea stranded on the British Coasts from 1948 to 1966 compiled by Fraser (No. 14, 1-65, 9 maps; British Museum (Natural History) 1974, £3.00) contains a full listing of the reported stranded cetaceans (with notes on a few sightings) on the British and Irish coasts for the eighteen year period to 1966 . It is unfortunate that even the most recent records in the report are now eight years old, and that the opportunity has not been taken to bring the list as nearly up to date as possible. Nevertheless, there is much of interest in the accumulated records despite their age, and there is good reason in bringing them all together in the hope that common patterns will emerge from the data.

Among the records of especial interest is the full documentation of two strandings of narwhal (Monodon monoceros), both in 1949 (February and July), a species known to have been found only three (or possibly four) times before. A pair of narwhals was also reported as sighted off the Orkneys in June 1949. 'The white whale (Delpinapterus leucas), only stranded once before since 1913, was sighted on three occasions (1948, 1950 and 1965) off the British Isles, and, as Fraser points out, was also reported off the French coast in December 1948, and in Dutch waters in June 1965 and 1966. The coincidence in some of these dates of sighting and later stranding suggests that the same specimens may have been involved in some cases, but this is not possible to confirm. What may also be significant (although Fraser does not comment on this) is that these two species are both Arctic cetaceans which occurred in unprecedented numbers in 1948-1949 in European waters following a winter of unusual severity in 1947-1948.

Other records of particular interest in Fraser's report are the first recorded occurrence of the pigmy sperm whale (Kogia breviceps), off Co. Clare, Ireland, in April 1966, and two unrecorded strandings of the euphrosyne dolphin (Stennella coeruleoalba). This species had hitherto only been reported twice (1937 and 1939) in British waters, but the two additional records predate these, one based on an old photograph of 1923, and the other on a skull in the British Museum collection, previously identified as a common dolphin, which was stranded in 1934.

The total number of identified stranding since record keeping began in 1913 now amounts to 1,550. Of these 631 were of the common porpoise (Phocoena phocoena), 185 of the bottle-nosed dolphin (Tursiops truncatus) and 135 of the common dolphin (Dolphinus delphis). By analysis of the occurrences of the common porpoise, Fraser has shown that strandings occur most frequently during the period July to October, with small peaks in January to March, and on the central and southern North Sea coast. Fraser cites earlier literature which suggests that there is an annual migration out of the Baltic between November and February, and conjectures that this may be correlated with the summertime peak of strandings on the East Coast of Britain. The pattern of records which Fraser presents is certainly in keeping with the suggestion that porpoises enter the North Sea mainly in the northern sector and then follow the main current systems southwards in an anti-clockwise direction. On the other hand, the incidence of strandings seems to be high in each of the major bights round the English and Welsh coasts, and the southern North Sea and the eastern English Channel can be seen as particularly large bights. The explanation for the distribution of porpoise strandings may thus be due to the configuration of the coast line and possibly the presence of shoal water, rather than to purely biological phenomena such as annual migrations of the animals.

\section{Lead accretion in alluvial deposits}

\section{from Peter D. Moore}

Plant Ecology Correspondent

THE release of undesirable but easily recognised substances into the environment, during such processes as mining and industrial smelting or by the explosion of nuclear devices, does have certain compensations. It can provide datum levels in recently deposited sediments which allow the calculation of accretion rates. For example, Bradbury and Waddington (in Quaternary Plant Ecology, edited by Birks and West, Blackwell, Oxford, 289; 1973) have used the abundance of haematite granules in the recent sediments of Shagawa Lake, Minnesota, to determine ediment ages. Haematite grains first appear in the sediments when iron ore mining began in the area in 1889 and reached a peak in 1902 when production was maximal; subsequently they declined gradually until 1951 when there was a sharp decrease corresponding to a decline in mining.

The isotope caesium-137 has been used as a datum in both peats and limnic sediments (for example, Pennington, Cambray and Fisher, Nature, 242, 324; 1973). Fallout reached a maximum in 1963 following the widespread proliferation of nuclear testing above ground. Lee and Tallis (Nature, 245, $216 ; 1973$ ) have used aerial lead fallout to provide datings of stratified peat deposits in the Southern Pennines.

Davies and Lewin (Envir. Pollut., 6, 49; 1974) have also studied lead, but this time in alluvial deposits of the River Rheidol. The build-up of alluvium in the meander loops of the river has been mapped or photographed on eight occasions during the past 130 years; this has allowed the successive zones of alluvial soil to be dated fairly accurately. The upper catchment of the Rheidol has been mined for lead since Roman times, but peak activity occurred during the nineteenth century. Davies and Lewin have analysed the zones of alluvial soils in an attempt to determine the effects of these activities 